\title{
THE ASCUS APEX IN LICHENIZED FUNGI III. THE PERTUSARIA-TYPE*
}

\author{
ROSMARIE HONEGGER $\ddagger$
}

\begin{abstract}
On the basis of light microscopic (LM), scanning electron microscopic (SEM) and transmission electron microscopic (TEM) investigations the Pertusaria-type of ascus is described as a particular functional type. The functionally unitunicate Pertusaria-type is characterized by its structure, staining properties, and by its particular mode of dehiscence. Tripartite ascus walls were observed in LM and TEM. The non-amyloid ascus wall is surrounded by a thin, amyloid outer layer. Both become amorphous at maturity and partly disintegrate. An apically thickened, amyloid inner layer reaches the base of the ascus. In its fine structure this amyloid inner layer resembles the material of the amyloid dôme of Lecanora-type asci. It plays an important rôle during dehiscence and spore discharge. An elongation process was observed prior to dehiscence, at the end of which the ascus tip is situated above the hymenial surface. Dehiscence occurs by bursting or splitting of the whole ascus tip. The Pertusaria-type might represent a side-branch of evolution from bitunicate to unitunicate forms within the Lecanorales.

Pertusaria-type asci are restricted to a small number of genera within the Pertusariaceae. A considerable heterogeneity in ascus structure and staining properties was observed within the Pertusariineae sensu Henssen \& Jahns (1973) and Henssen (1976).
\end{abstract}

\section{Introduction}

The significance of ascus structure and function as a diagnostic feature for the natural classification of lichenized and non-lichenized ascomycetes has been demonstrated and discussed by various mycologists and lichenologists (Luttrell 1951, Chadefaud 1973, Letrouit-Galinou 1973, Beckett 1981, Bellemère \& Letrouit-Galinou 1981, Honegger 1982).

Four different functional ascus types have so far been described within the Lecanorales using TEM techniques; their distribution and hypothetical relationships are discussed by Honegger (1978a, $b, c, 1980,1982)$. Two functionally bitunicate forms (in the sense of Luttrell 1951), and two unitunicate types were found. Additionally various other ascus types may be observed within the Lecanorales sensu Henssen \& Jahns (1973), whose structure and function are not yet sufficiently investigated. On the basis of ascus structure and function, some of the suborders now recognized in the Lecanorales are rather heterogeneous. One of these heterogeneous groupings is the Pertusariineae sensu Henssen \& Jahns (1973) and Henssen (1976), part of which is investigated in the present paper.

The asci of different Pertusaria species have been studied by Ziegenspeck (1926), Galinou \& Chadefaud (1953), Letrouit-Galinou (1973), Henssen (1976) and Dibben (1980). On the basis of structural and cytochemical investigations at the LM level, Letrouit-Galinou (1973) interpreted the ascus of Pertusaria pertusa as a 'type eu-archaeascé ', although its particular bivalve mode of dehiscence was

*II in Lichenologist 12: 157-172(1980).

¥Institute of Plant Biology, Cytology Department, University of Zürich, Zollikerstrasse 107, CH-8008 Zürich, Switzerland. 


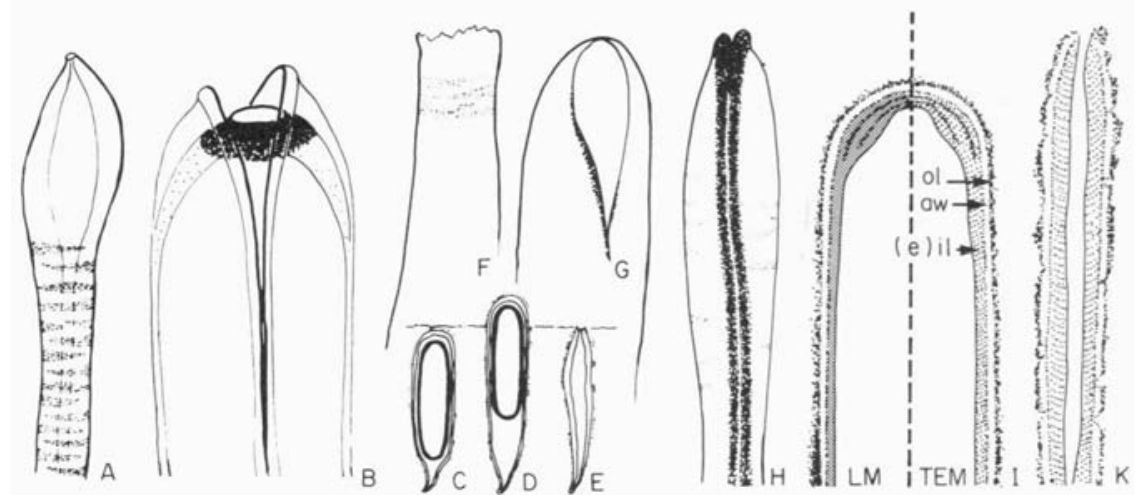

Fig. 1. Diagrammatic interpretation of the Pertusaria-type ascus. A, LM investigation of the Pertusaria ascus after spore discharge according to Ziegenspeck (1926); the striate pattern was interpreted as functionally similar to muscle fibres. B, LM study of the ascus of Pertusaria pertusa after spore discharge according to Galinou \& Chadefaud (1953) and Dibben (1980). C-E, LM of mature asci of Pertusaria amara prior (C, D) and after spore discharge (E). After an elongation process the ascus tip is situated above the hymenial surface (D). F-H, LM of three Pertusaria asci after spore discharge: Pertusaria leucostoma (F), P. amara (G), and P. pertusa (H). I, LM and TEM of the mature Pertusariatype ascus prior to elongation and spore release; aw, ascus wall; (e) il, elastic inner layer; ol, outer layer (fuzzy coat). K, TEM interpretation of the ascus wall layers after spore release; amorphous flecks of the material of the primary ascus wall and its outer layer are overlaying the elastic inner layer.

noted. Her 'type eu-archaeascé ', mainly based on structural features revealed in LM, corresponds more or less to the Lecanora-type of Honegger $(1978 a, b)$ which is defined by its staining properties and by its fine structure and function during ascospore maturation, dehiscence and spore release. One amongst other characteristics of the Lecanora-type is its rostrate method of dehiscence.

A particularly interesting behaviour of the asci of a Pertusaria species during dehiscence and spore discharge was reported by Ziegenspeck (1926), whose original comparative investigations of ascus structure and function in lichenized and non-lichenized fungi have not received enough attention. With the aid of a surface microscope commonly used in metallurgy and mineralogy, Ziegenspeck investigated the hymenial surface of various freshly collected ascomycetes, and thus was able to observe the ascus tips during dehiscence and spore discharge. Focusing on the narrow pore of unidentified four-spored Pertusaria species (probably $P$. leucostoma), he noted a considerable elongation of the asci prior to spore release, until the asus apex became visible in the pore. In LM preparations of empty Pertusaria asci, he detected a special striate pattern (Fig. 1A) which he interpreted as functionally similar to muscle fibres, and thus as the generator of the forces necessary for ascus elongation and ascospore ejection.

In the present investigation, ascus structure and function in three Pertusaria species are described by LM and partly with SEM and TEM techniques, and compared with other ascus types.

\section{Materials and Methods}

Material: Pertusaria leucostoma (Bernh.) Massal.: Switzerland, St Galler Oberland, on Fagus sylvatica near St Margrethenberg; May 1975. Pertusaria amara var. slesvicensis Erichsen: France, Brittany, 
on Fagus sylvatica, forêt de Coatloc'h near Scaër, S-Finistère; March 1973. Pertusaria pertusa (Weigel.) Tuck.: France, Brittany, on Fagus sylvatica, forêt du Cranou west of Le Faou, Finistère; March 1976. Ochrolechia parella (L.) Massal.: France, Brittany, granitic rocks at the seashore in Roscoff, N-Finistère; March 1973. Ochrolechia frigida (Sw.) Lynge: Iceland, Vikurbakki north of Akureyri, on plant detritus and mosses; August 1978. Placopsis gelida (L.) Lindsay: Iceland, on old lava fields next the Herdubreid hut, east of Myvatn. September 1978. Icmadophila ericetorum (L.) Zahlbr.: Switzerland, Klöntal, Kt. Glarus, on dead fir wood; July 1980. Trapelia coarctata (Sm. \& Sowerby) M. Choisy: Switzerland, Schwyalp, Klöntal, Kt. Glarus; July 1980. Trapelia involuta (Taylor) Hertel: Austria, Tirol, Salzburgerhütte near Kaprun; September 1973. Coccotrema cucurbitula (Mont.) Müll. Arg.: Chile, Prov. Llanquihue, Parque Nacional Perez Rosales, on dead wood in the rainforest at the lake Todos los Santos; November 1973, herb. Henssen 24 303a. Coccotrema cucurbitula (Mont.) Müll. Arg.: Argentinia, Prov. Rio Negro, Puerto Blest, on Nothofagus dombeyi in the rainforest of the Parque Nacional Nahuel Huapi; December 1973, herb. Henssen 24 609a.

Light microscopy (LM): Photographs of whole ascomata were taken with a Zeiss Tessovar.

Ascus preparations for LM investigations were made from either fresh, or glutaraldehyde-fixed material, with the exception of Coccotrema cucurbitula, where herbarium material was available. With the aid of a dissecting microscope very small parts of the hymenium containing single or few asci were cut out and transferred to either lactophenol-cottonblue, Lugol's solution, or to a saturated solution of potassium hydroxide, then washed and transferred to Lugol. Janus green, ammoniacal congo red and Waterman's ink were occasionally used. LM preparations were examined in a Zeiss Photomikroskop II equipped with phase contrast.

Scanning electron microscopy (SEM): Air-dryed ascomata were gold-sputtered and examined with a Cambridge Stereoscan.

Transmission electron microscopy (TEM): Asci of freshly collected Pertusaria pertusa were fixed in $2 \cdot 5 \%$ glutaraldehyde in phosphate buffer, $\mathrm{pH} 7 \cdot 1$, for $4 \mathrm{~h}$ at room temperature, and post-fixed in either $2 \%$ osmium tetroxide, or $1 \%$ potassium permanganate. After dehydration in acetone and embedding in Spurr's medium, ultrathin sectioning was carried out on a Reichert OM U2 ultramicrotome equipped with a Diatome diamond knife. Serial sections were mounted on one slot grids, stained with uranyl acetate and lead citrate, and examined in a Hitachi $\mathrm{HS} 8$ electron microscope at $50 \mathrm{kV}$.

\section{Results}

\section{Light and scanning electron microscopy}

The large asci of Pertusaria amara, P. leucostoma and P. pertusa are embedded in a weakly to non-amyloid hymenial gelatine. Three easily distinguishable wall layers were observed: a thin, amyloid outermost layer ('fuzzy coat'), a nonamyloid primary ascus wall, and a strongly amyloid apically thickened inner layer which reaches the base of the ascus (Figs 1I, 3A-B). A 'nasse apicale' may occasionally be observed, mainly in pre-meiotic asci. Treatment with potassium hydroxide prior to staining with Lugol's solution does not change the staining properties of either asci or hymenial gelatine.

At maturity the ascus tips of the Pertusaria species investigated almost reach the hymenial surface (Figs 1C, 2A, D). Prior to ascospore discharge an elongation of the whole ascus was observed, at the end of which the ascus tip is situated above the hymenial surface (Figs 1D, 3B). This phenomenon was described by Ziegenspeck (1926) in a verrucate Pertusaria species and seen quite well here in P. leucostoma (Fig. 2A). It is, however, most distinctly visible in Pertusaria species with disciform ascomata, such as $P$. amara, where mature asci appear as orange, 

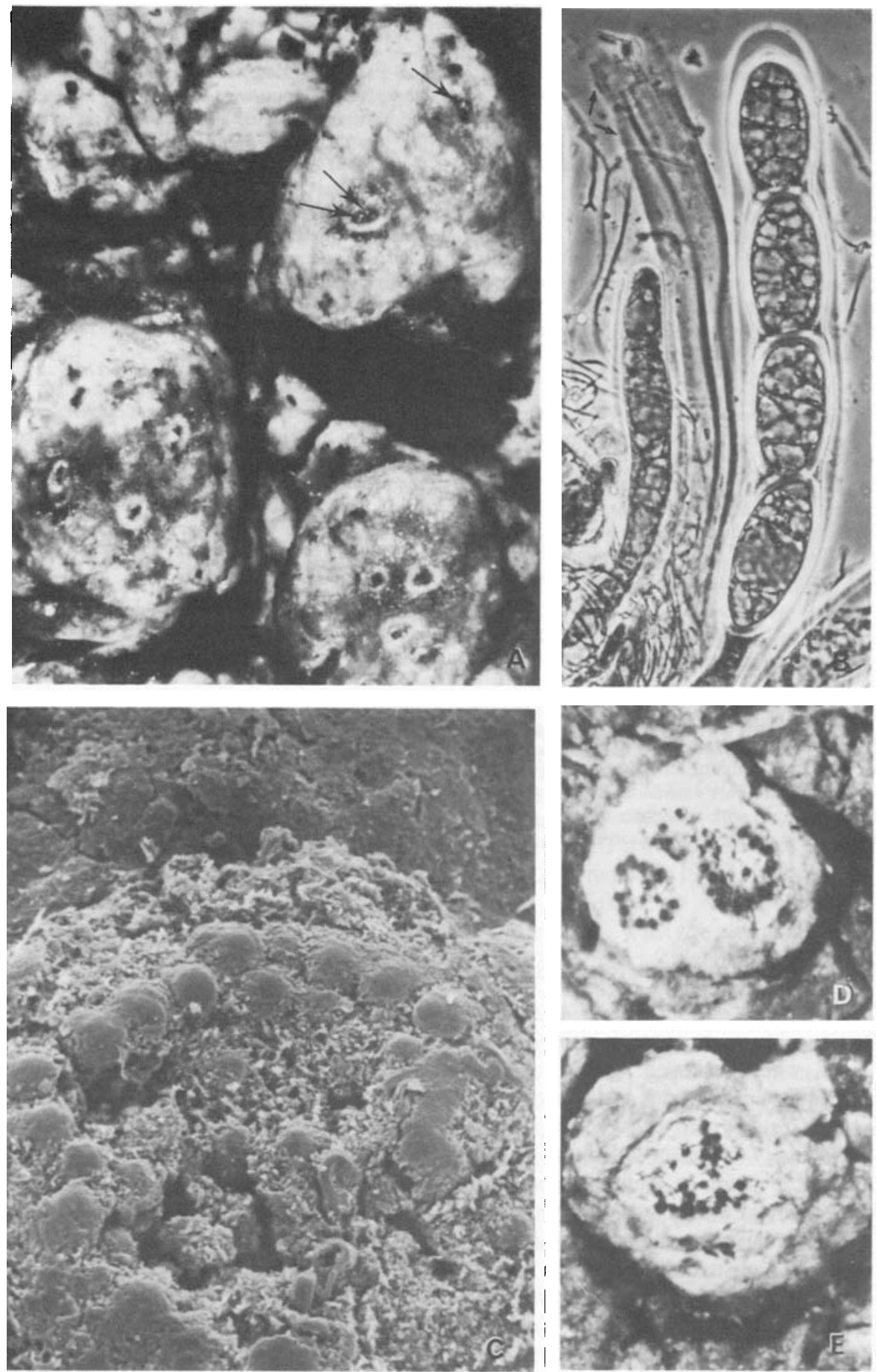

Fig. 2. Ascocarps of Pertusaria leucostoma (A-B) and P. amara (C-E). A, Verrucae of P. leucostoma; the arrows indicate elongated asci whose tips become visible within the ostiole, $\times 25$. B, LM of a young, an empty, and a mature, elongated ascus of $P$. leucostoma; the arrows indicate a zone with a slightly striated pattern; in lactophenol-cottonblue, $\times 370 . \mathrm{C}$, SEM of the disciform ascoma of Pertusaria amara; the tips of mature, elongated asci are seen as rounded spots, $\times 170$. D-E, LM of $P$. amara ascomata. The tips of elongated asci appear as orange (D) or, after addition of Lugol's solution, as blue dots $(\mathrm{E})$ above the hymenial surface, $\times 30$ 

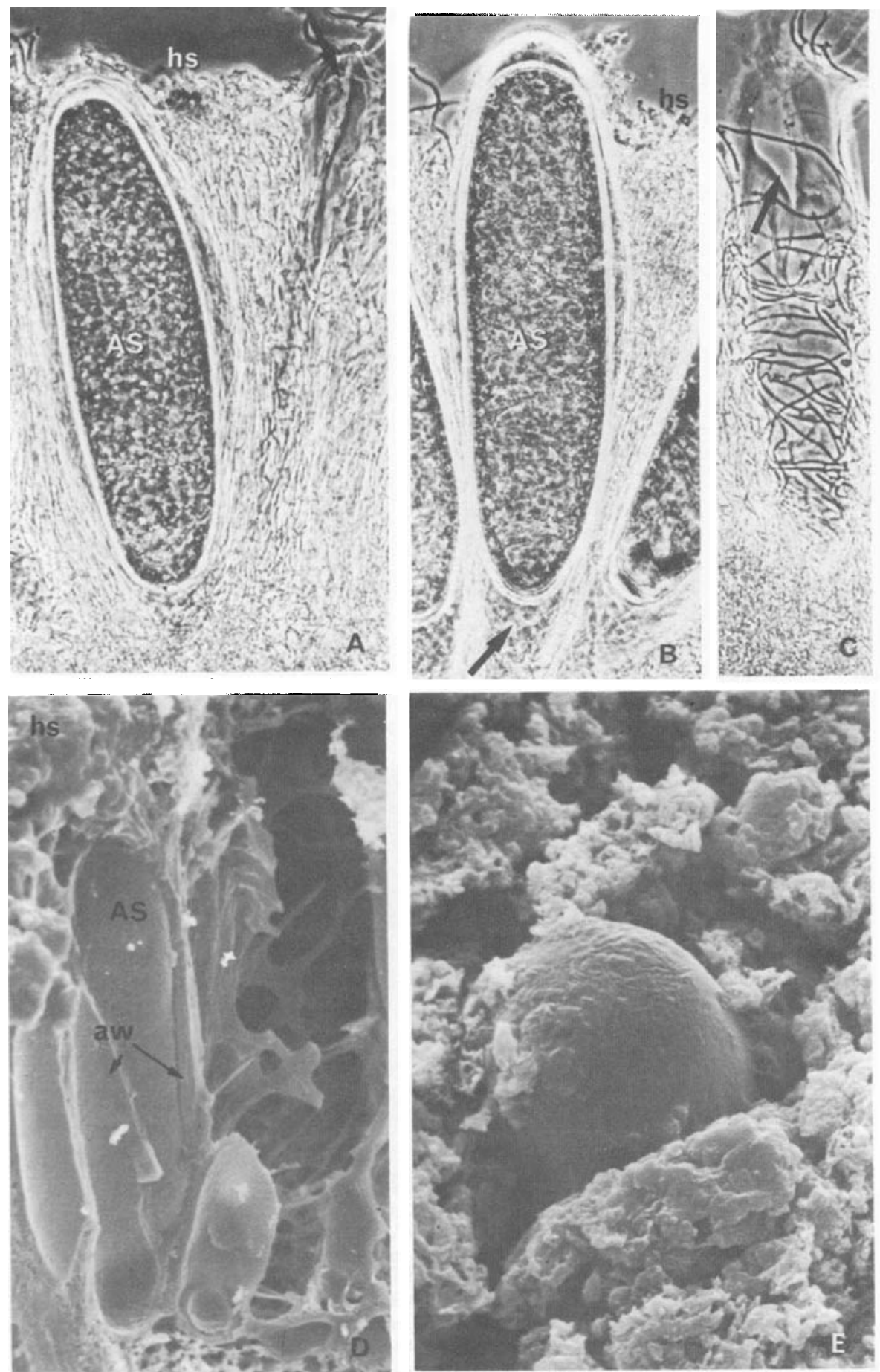

FIG. 3. Pertusaria-type asci in P. amara. A, LM of a mature and an empty ascus (arrow); hs, hymenial surface; AS, ascospore. B, LM of a mature ascus after elongation; the ascus tip is seen above the hymenial surface, while an enlargement of the ascus cytoplasm (probably due to the imbibition of water) is seen in the basal parts (arrow). C, LM of the ascus after spore discharge; dehiscence occurred by random splitting of the ascus apex (arrow). A-C, lactophenol-cottonblue, $\times 360 . \mathrm{D}, \mathrm{SEM}$ preparation of the ascoma; several mature asci are fractured, and their broken walls (aw) and the outer layer of an ascospore (AS) are seen, $\times 400$. E, SEM of the hymenial surface with the tip of an elongated ascus. $\times 940$. 


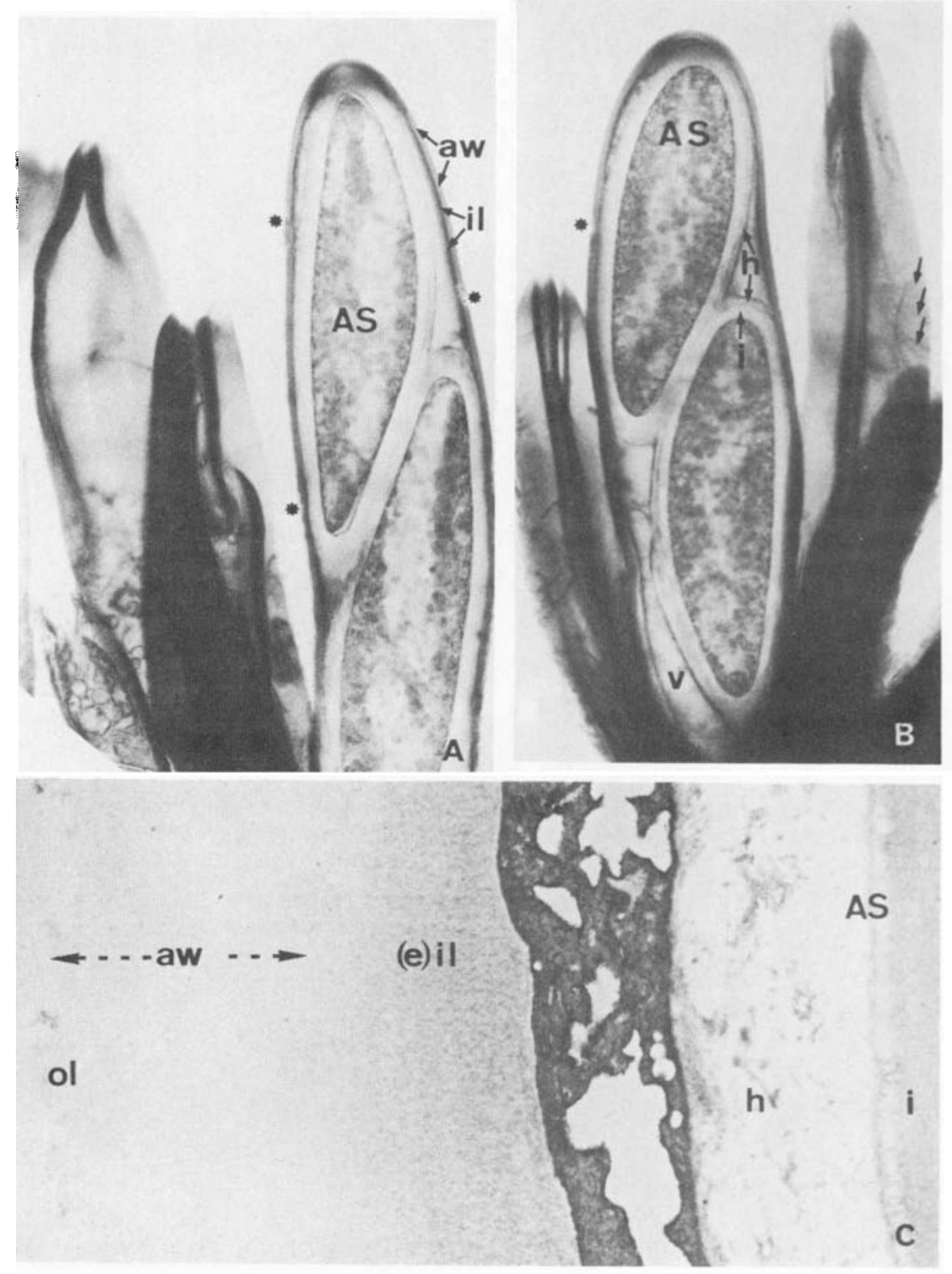

FIG. 4. LM and TEM of the Pertusaria-type ascus in P. pertusa. A-B, LM of mature, elongated asci before and after spore discharge; Lugol staining, the non-amyloid ascus wall and its amyloid outer layer (aw) and partly disintegrated (*); the amyloid inner layer is apically thickened and reaches the base of the ascus; Dehiscence occured in a bivalve manner, but it is not clearly seen how far the slit reaches; the ascospores (AS) have two wall layers, a hard, rigid inner one (i) and a gelatinous halo (h) outside, $\times 250$. C, TEM of part of the ascus and ascospore wall; aw, electron-transparent primary ascus wall with a weakly electron-dense outer layer (ol), (e) il, elastic inner layer with an electrontransparent matrix and electron-dense inclusions; AS, ascospore; i, inner layer of ascospore wall; $h$, halo; outer layer of ascospore wall, $\times 3800$. 
shiny dots above the hymenial surface (Figs $2 \mathrm{C}-\mathrm{E}, 3 \mathrm{~B}, \mathrm{E}$ ). When Lugol's solution is added to whole hymenia the ascus tips turn dark blue (Fig. 2E), but in bursting or splitting ascus tips the upper ascospore is seen as an orange dot within the dark blue envelope of the ascus wall.

It is not understood where the forces for this elongation process and for ascospore ejection originate. A contraction of the basal parts of the ascus, as suggested by Ziegenspeck (1926), was not observed. Most probable is a rapid increase in the internal osmotic pressure of the ascus by imbibition of water, eventually correlated with transformation of storage products localized in the remaining ascus cytoplasm. It is particularly interesting that the ascospore $(\mathrm{s})$ are always located at the tips of the elongated asci (Figs $1 \mathrm{D}, 2 \mathrm{~B}, 3 \mathrm{~B}, 4 \mathrm{~A}-\mathrm{B}$ ). A large vacuole was seen in the basal parts of elongated Pertusaria pertusa asci (Fig. 4B).

During dehiscence, the whole ascus wall splits or bursts (Figs $1 \mathrm{~F}-\mathrm{H}, 2 \mathrm{~B}, 3 \mathrm{~A}$, C, 4A-B). Pertusaria-type asci are functionally unitunicate in the sense of Luttrell (1951), although their thick walls are multilayered. The splitting process may occur in a bivalve manner, as observed in most of the Pertusaria pertusa asci studied (Figs $1 \mathrm{H}, 4 \mathrm{~A}-\mathrm{B}$ ), or rather randomly, as it is seen in P. amara (Figs $1 \mathrm{G}$, $3 \mathrm{~A}, \mathrm{C})$. In $P$. leucostoma dehiscence occurs by simple bursting of the ascus apex (Figs 1F, 2B). The different wall layers do not separate from each other during the elongation and dehiscence of Pertusaria asci, but the weak and partly amorphous ascus wall and its fuzzy coat may locally disintegrate during the elongation process (Figs $4 \mathrm{~A}-\mathrm{B}$ ). In this way a weakly visible striate pattern develops, which can occasionally be observed in empty asci (Figs 1A, F, H, 2B, 4B).

In none of the preparations investigated was a situation resembling that described by Galinou \& Chadefaud (1953) and Dibben (1980) observed, i.e. where one or more outer layers of the Pertusaria pertusa ascus wall split in a bivalve manner, whilst the inner layer(s) remained intact, revealing an amyloid pore at the apex (Fig. 1B). In the fresh material investigated here, mature asci had a very weak, locally disintegrating ascus wall and fuzzy coat (Figs 4A-B). A separation of this amorphous wall material from the inner layer as a complete sheet was never observed. It is, however, imaginable that such a situation might occur after vigorously squashing young, pre-mature asci, but with such treatment no information can be obtained on the dehiscence mechanisms at maturity.

\section{Transmission electron microscopy}

It was difficult to obtain good TEM preparations from Pertusaria pertusa asci as the thick ascus and ascospore walls were frequently not sufficiently penetrated by the fixatives and embedding media, and thus could not be properly sectioned.

The tripartite ascus wall observed in LM was also seen in TEM preparations. A thin, slightly electron-dense outer layer (fuzzy coat) was found outside the electron-transparent primary ascus wall (Fig. 4C). The whole length of the apically thickened inner layer is seen as an electron-transparent matrix with electron-dense inclusions. Similar structures were observed in the apical dome of the Lecanora-type asci (Honegger 1978a, b), and, to a certain degree, in the expansible inner layer (endoascus) of the bitunicate Rhizocarpon-type (Honegger $1978 c, 1980$ ). A striate pattern was observed in apical thickening of the inner layer in mature asci (Fig. 5). 


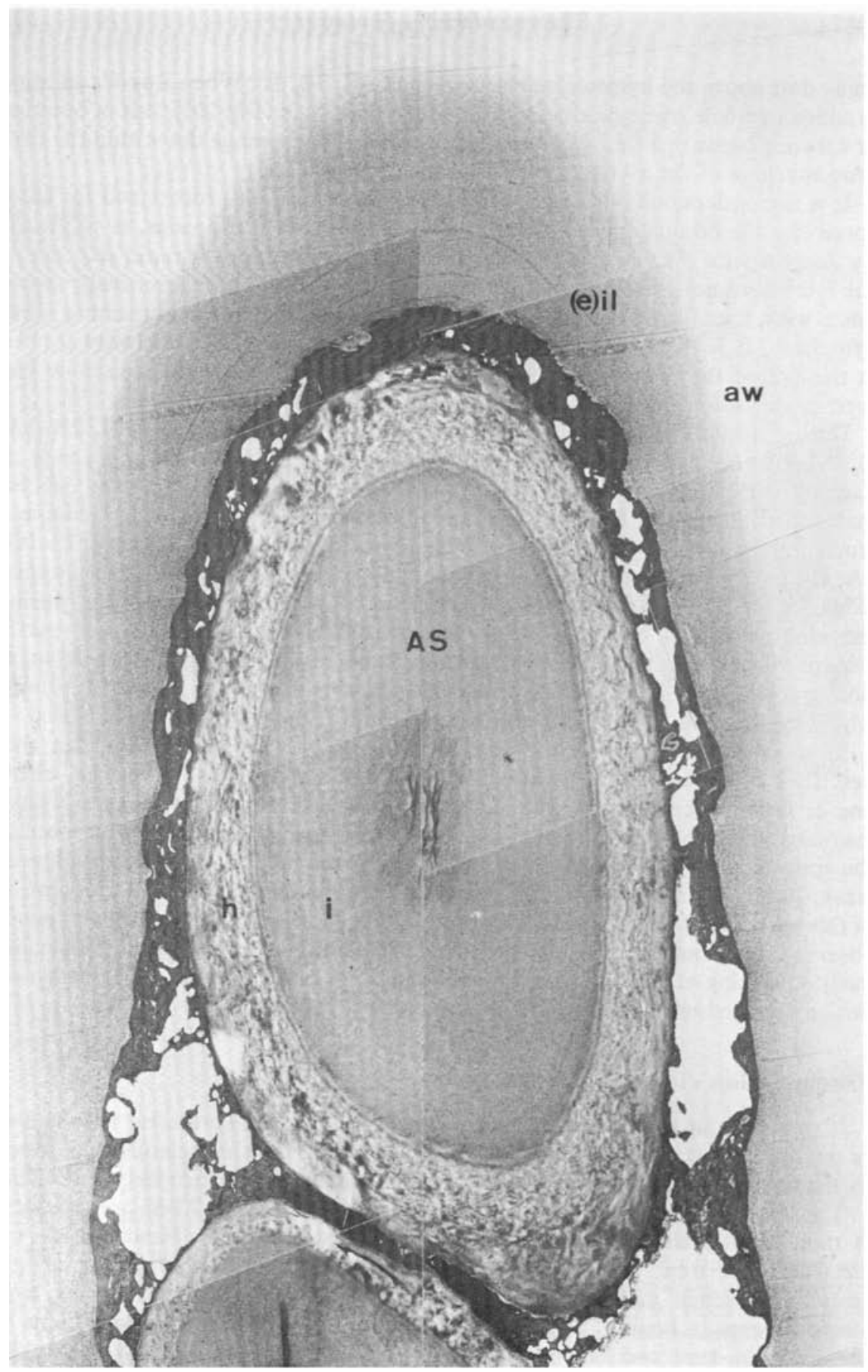

FIG. 5. TEM of part of a median longitudinal section of part of the ascus of Pertusaria pertusa after elongation, aw, ascus wall, partly disintegrated and only weakly visible; (e) il, elastic inner layer; AS, tangential section of an ascospore (the ascus investigated here contained three ascospores), with the halo ( $h$ ) and inner layer (i) of the spore wall; $\times 1800$. 
After the elongation process the material of the ascus wall and its outer layer is seen as amorphous flecks overlaying the massive, elastic inner layer (Fig. 5).

As noted by Pyatt (1969), the fine structure of the ascospore wall is particularly interesting. Two different wall layers were seen in LM and in TEM preparations. The inner is homogeneous in structure and of rigid consistency, whilst the outer forms a gelatinous halo (Figs 4C, 5). Structurally, the halo of Pertusaria ascospores resembles that observed in Rhizocarpon (Honegger 1980).

\section{Discussion}

With its particular structure and function, the Pertusaria-type ascus is clearly distinguishable from the other functional ascus types so far described within the Lecanorales. According to Chadefaud and his co-workers, the ascus of Pertusaria pertusa represents a very archaic form (Chadefaud 1973, Galinou \& Chadefaud 1953, Letrouit-Galinou 1973). With its complete inner layer and its special type of dehiscence, the Pertusaria-type ascus might equally well be interpreted as a descendant of a bitunicate form, and thus as an evolutionary side-branch from bitunicate to unitunicate forms within the Lecanorales. Particularly interesting are the investigations of Erbisch (1969) on the early stages of ascus initiation in various Pertusaria species. He found a very unusual type of crozier formation in Pertusaria alpina, whereas no croziers were detected in $P$. laevigata, $P$. velata, $P$. pertusa or $P$. pustulata. Crozier formation has been supposed to be an ancient type of ascus initiation. Thus, the Pertusaria-type of ascus initiation without the prior formation of a crozier was interpreted as the result of an evolved process rather than an archaic one (Erbisch 1969).

The Pertusaria-type ascus, with its particular staining properties and function, is probably restricted to a small number of genera. The Pertusariaceae, and even more so the suborder Pertusariineae of the Lecanorales sensu Henssen \& Jahns 1974), Henssen (1976), and Henssen et al. (1981), are heterogeneous with regard to ascus structure and staining properties. Representatives of a few genera were compared on the LM level, but further investigations, especially of the fine structure and function, are needed.

Very thick-walled asci were observed in Ochrolechia parella and O. frigida (Figs $6 \mathrm{~A}-\mathrm{B})$. The inner layer is apically thickened, but the staining properties of the different wall layers could not be properly analysed, since the whole ascus turns so intensely blue after the addition of iodine that no details could be resolved in LM (Fig. 6B). Pre-treatment with potassium hydroxide does not change the staining properties of Ochrolechia asci or of the strongly amyloid hymenial gelatine. Dehiscence occurs by a bursting of the ascus apex (Fig. 6A-B).

Placopsis was classified in the Lecanoraceae by Ozenda \& Clauzade (1970), in the Trapeliaceae ("a family with no clear relationships') by Poelt (1974), but was interpreted as a genus of the Pertusariaceae by Henssen \& Jahns (1973). The thin-walled asci of Placopsis gelida are embedded in a non-amyloid hymenial gelatine. Ascus wall and apical dome are non-amyloid, but a thin, outermost layer stains blue with iodine (Figs 6I, K). Potassium hydroxide does not change the staining properties of either the asci or the hymenial gelatine, but it causes an enormous swelling of the ascus wall layers and ascospores. Dehiscence occurs by a bursting of the ascus apex. Similar staining properties and function were 

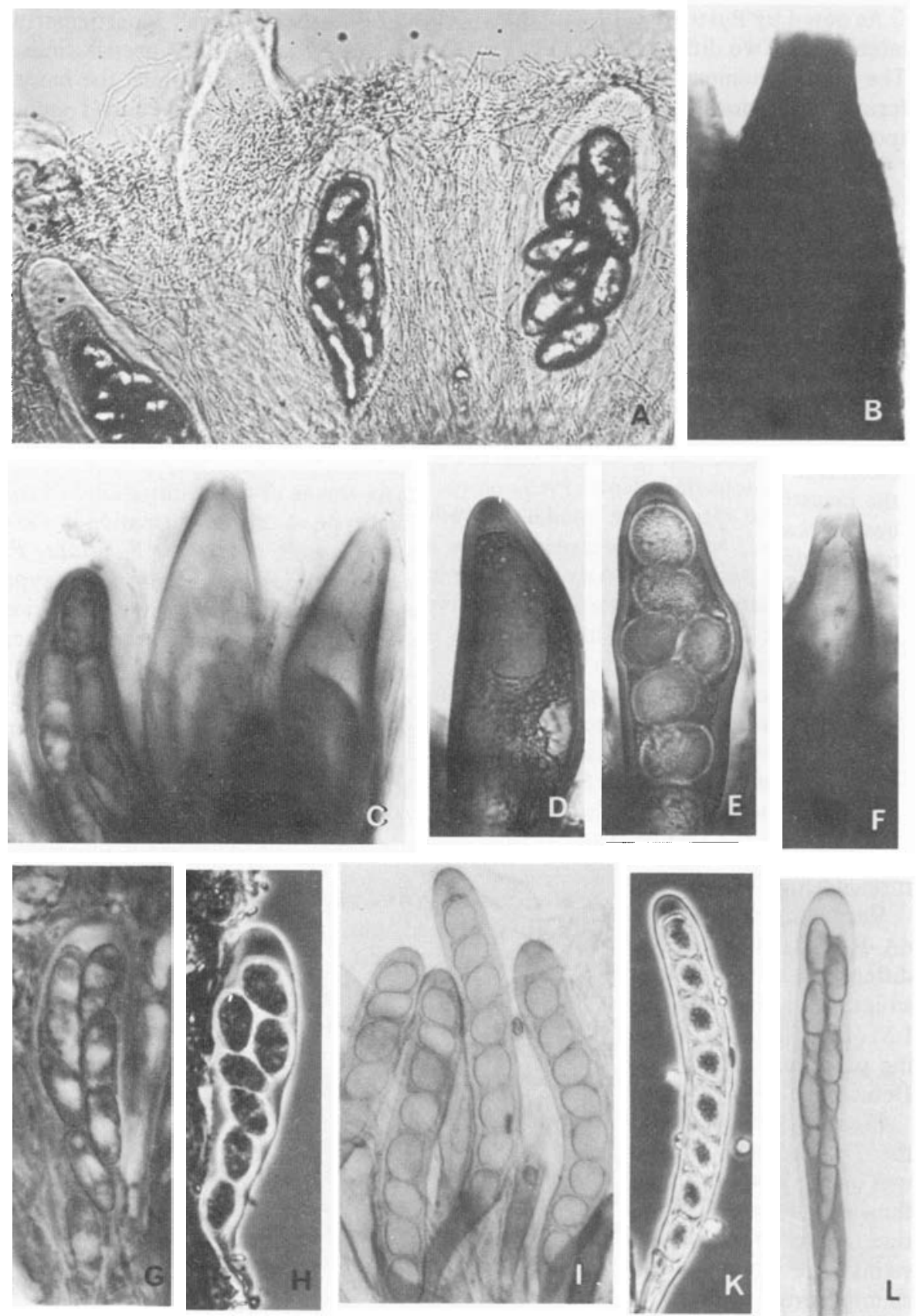
observed by Hertel (1970) in the asci of Icmadophila ericetorum (Fig. 6L), a member of the Baeomycetaceae, whose taxonomic position is also a matter of debate (Letrouit-Galinou 1973, Honegger \& Brunner 1981, Honegger 1982).

The inclusion of the Trapeliaceae in the Pertusariineae by Henssen \& Jahns (1973) was based mainly on certain morphological criteria. Hertel (1970) and Poelt (1974) concluded, on the basis of comparative LM investigations of ascus structure and function, that the taxonomic position of the Trapeliaceae could not yet be properly defined. The ascus of Trapelia coarctata resembles in its structure and function those of Placopsis and Icmadophila (Figs 6I-L), but it differs from both in its staining properties. Trapelia coarctata and $T$. involuta asci turn yellow to brown with iodine, and no amyloid structures were observed unless the material was pre-treated with potassium hydroxide (Figs $6 \mathrm{G}, \mathrm{H}$ ). Potassium hydroxide pretreatment causes a dissolution of the hymenial gelatine and an enormous swelling of the ascus wall which then turns blue with Lugol's solution.

The genus Coccotrema was included in the Pertusariaceae by Oshio (1968) and Poelt (1974). Brodo (1973) claimed that Coccotrema has the following features in common with the Pertusariaceae: sunken ascocarps, bivalve ascus dehiscence ascospore structure, and the occurrence of $\beta$-depsidones. On the other hand, Coccotrema differs from the Pertusariaceae by its possession of a distinct excipulum, of periphyses around the ostiole, and by its lack of isolichenin (amyloid structures) in the hymenium (Brodo 1973). The particular ascomatal ontogeny and morphology of Coccotrema and Lepolichen were described by Henssen (1976), who found enough corresponding features with Pertusaria for a classification of the Coccotremataceae within the Pertusariineae sensu Henssen \& Jahns (1973).

The slightly pyriform, thick-walled and non-amyloid asci of Coccotrema cucurbitula are embedded in a non-amyloid hymenial gelatine. Ascus wall and hymenial gelatine stain yellow to brown with Lugol's solution. Pre-treatment with potassium hydroxide causes an enormous swelling of the ascus wall layers and of the ascospores (Figs 6C-E). After potassium hydroxide treatment, the ascus wall and the hymenial gelatine turn blue with iodine. Dehiscence may occur in a bivalve manner, but in most of the asci investigated spore discharge occurred by a simple bursting of the ascus tip (Figs $6 \mathrm{C}, \mathrm{F}$ ).

FIG. 6. LM of asci of members of various genera classified within the Pertusariineae sensu Henssen \& Jahns (1973) and Henssen (1976). A-B, Ochrolechia frigida, pre-treated with potassium hydroxide; $B$, empty after addition of Lugol's solution; the ascus wall layers stained so intensely blue that no details could be resolved, $\times 225$. C-F, Coccotrema cucurbitula, mature asci before and after spore release, stained with Lugol's solution: C, ascus wall and hymenial gelatine turn yellow to brown, $\times 290$. D-F, Coccotrema cucurbitula asci pre-treated with potassium hydroxide and stained with Lugol's solution, ascus wall layers and ascospore are swollen, the hymenial gelatine and the ascus wall turn blue with iodine, $\times 350 . \mathrm{G}-\mathrm{H}$, Trapelia coarctata: $\mathrm{G}$, stained with Lugol, ascus wall and hymenial gelatine turn yellow to brown, $\times 900 ; \mathrm{H}$, Lugol staining after pre-treatment with potassium hydroxide, which caused an enormous swelling of the ascus wall and the ascospores, the hymenial gelatine and the ascus wall turn blue with iodine, $\times 560.1, \mathrm{~K}$, Placopsis gelida, pre-treated with potassium hydroxide and stained with Lugol; the hymenial gelatine and the ascus wall are non-amyloid, an outermost, apically slightly thickened fuzzy coat turns blue with iodine, $\times 650$. L, Icmadophila ericetorum stained with Lugol; hymenial gelatine and ascus wall are non-amyloid, but a thin, apically thickened fuzzy coat stains blue with iodine, $\times 690$; Icmadophila is not classified within the Pertusarineae, but its asci show similarities with those of Placopsis $(\mathrm{I}, \mathrm{K})$. 
The data gathered here on ascus structure, function and staining properties within the Pertusariineae sensu Henssen and Jahns (1973), Henssen (1976), and Henssen et al. (1981), indicate a surprisingly high heterogeneity. It has to be pointed out that ascus structure, function and cytochemistry, as well as the staining properties of the hymenial gelatine, proved to be very stable features within natural groupings so far investigated within the Lecanorales (Honegger 1982). Thus, these characteristics could be used for the revision of difficult and formerly heterogeneous groups of lichenicolous and lichenized ascomycetes (Hafellner 1979, Kilias 1981). Further investigations are needed to elucidate whether the Pertusariineae are an extremely heterogenous natural group, or whether they represent an artificial assembly of not so closely related elements with some convergent features. Since ascus structure and function in these genera is very simple and ascomatal ontogeny is not always easy to interpret (e.g. Coccotrema), the search for further good criteria for the natural classification of lichenized ascomycetes, eventually on the ultrastructural and biochemical level, is most important. Mechanisms of ascospore delimitation, type of storage products, and type of mycobiont-phycobiont contact have been proposed as possible structures to investigate (Honegger 1982). The structure and chemical composition of the hyphal wall in the symbiotic and cultured state might supply additional information on natural relationships.

My thanks are due to Drs J. Dibben and I. M. Brodo for stimulating discussions; to Prof. Dr Aino Henssen for the loan of Coccotrema specimen; and to Dr D. L. Hawksworth for critically reading and correcting my manuscript.

\section{REFERENCES}

Beckett, A. (1981) The ascus with an apical pore: development, composition and function. In Ascomycete Systematics (D. R. Reynolds, ed.): 7-26. New York, Heidelberg, Berlin: Springer.

Bellemère, A. \& Letrouit-Galinou, M. A. (1981) The lecanoralean ascus: an ultrastructural preliminary report. In Ascomycete Systematics (D. R. Reynolds, ed.): 54-70. New York, Heidelberg, Berlin: Springer.

Brodo, I. M. (1973) The lichen genus Coccotrema in North America. Bryologist 76: 260-270.

Chadefaud, M. (1973) Les asques et la systematique des ascomycètes. Bull. trimest. Soc. mycol. Fr. 99: $127-170$.

Dibben, M. J. (1980) The chemosystematics of the lichen genus Pertusaria in North America north of Mexico. Milwaukee Public Museum, Publs. Biol. Geol. 5: 1-162.

Erbisch, F. H. (1969) Ascus and ascospore development of five species of the lichen-forming genus Pertusaria. Bryologist 72: 178-199.

Galinou, M. A. \& Chadefaud, M. (1953) Sur l'asque des lichens du g. Pertusaria et son importance phylogénétique. C. r. hebd. Séanc. Acad. Sci., Paris, sér. D, 237: 1178-1180.

Hafellner, J. (1979) Karschia. Revision einer Sammelgattung an der Grenze von lichenisierten und nichtlichenisierten Ascomyceten. Beih. Nova Hedwigia 62: 1-248.

Henssen, A. (1976) Studies in the developmental morphology of lichenized ascomycetes. In Lichenology: Progress and Problems (D. H. Brown, D. L. Hawksworth and R. H. Bailey, eds.): 107-138. London, New York: Academic Press.

Henssen, A. \& Jahns, H. M. (1973) ['1974'] Lichenes. Eine Einführung in die Flechtenkunde. Stuttgart: Thieme.

Henssen A. [in cooperation with G. Keuck, B. Renner, \& G. Vobis] (1981) The lecanoralean centrum. In Ascomycete Systematics (D. R. Reynolds, ed.): 138-234. New York, Heidelberg, Berlin: Springer.

Hertel, H. (1970) Trapeliaceae-eine neue Flechtenfamilie. Vortr. Bot. Ges [Dtsch. Bot. Ges.], n.f. 4: $171-185$.

Honegger, R. (1978a) Licht- und elektronenoptische Untersuchungen an Flechten-Asci vom Lecanoratyp. Dissertation, Universität Basel. 
Honegger, R. (1978b) The ascus apex in lichenized fungi I. The Lecanora-, Peltigera-and Teloschistestypes. Lichenologist 10: 47-67.

Honegger, R. (1978c) Ascocarpontogenie, Ascusstruktur und-funktion bei Vertretern der Gattung Rhizocarpon. Ber. dtsch. Bot. Ges. 91: 579-594.

Honegger, R. (1980) The ascus apex in lichenized fungi II. The Rhizocarpon-type. Lichenologist 12: $157-172$.

Honegger, R. (1982) Ascus structure and function, ascospore delimitation, and phycobiont cell wall types associated with the Lecanorales (lichenized ascomycetes). F. Hattori Bot. Lab. 52: 417-429.

Honegger, R. \& Brunner, U. (1981) Sporopollenin in the cell walls of Coccomyxa and Myrmecia phycobionts of various lichens: an ultrastructural and chemical investigation. Can. F. Bot. 59: 2713-2734.

Kilias, H. (1981) Revision gesteinsbewohnender Sippen der Flechtengattung Catillaria Massal. in Europa (Lecanorales, Lecideaceae). Herzogia 5: 209-448.

Letrouit-Galinou, M. A. (1973) Les asques des lichens et le type archaeascé. Bryologist 76: 39-58.

Luttrell, E. S. (1951) Taxonomy of the pyrenomycetes. Univ. Missouri Stud. 24(3): 1-120.

Oshio, M. (1968) Taxonomical studies on the family Pertusariaceae of Japan. F. Sci. Hiroshima Univ., ser. B, div. 2 (Bot.) 12: 81-163.

Ozenda, P. \& Clauzade, G. (1970) Les Lichens. Étude Biologique et Flore Illustré. Paris: Masson \& Cie.

Poelt, J. (1974) ['1973'] Systematic evaluation of morphological characters. In The Lichens (V. Ahmadjian \& M. E. Hale, eds): 91-115. New York, London: Academic Press.

Pyatt, F. B. (1969) The ultrastructure of the ascospore wall of the lichen Pertusaria pertusa. Trans. Br. mycol. Soc. 52: 167-169.

Ziegenspeck, H. (1926) Schleudermechanismen von Ascomyceten. Bot. Arch. Königsberg 13: 341-381.

Accepted for publication 1 April 1982 
Downloaded from https:/www.cambridge.org/core. University of Basel Library, on 11 Jul 2017 at 09:04:05, subject to the Cambridge Core terms of use, available at https:/www.cambridge.org/core/terms. https://doi.org/10.1017/S0024282982000437 